\title{
Factors affecting addiction severity index (ASI) among clients enrolled in methadone maintenance treatment (MMT) program in Myanmar
}

\author{
Sun Tun ${ }^{1,2^{*}}$, B. Vicknasingam ${ }^{2}$ and Darshan Singh ${ }^{2}$
}

\begin{abstract}
Background: Opioid substitution with methadone maintenance treatment (MMT) is shown to reduce illicit opioid use and renew social functioning. Understanding factors that undermine clients' social functioning during MMT treatment is vital for improving treatment compliance and quality of life.

Method: A total of 210 respondents who were already enrolled in a formal MMT program in Myanmar were recruited from five cities through stratified random sampling for this cross-sectional study. The addiction severity index (ASI) was used to objectively assess respondents social functioning in the last 30 days. Higher ASI scores denote poorer social functioning.

Result: Respondents total ASI scores in the respective domains were: employment (47.4\%), alcohol (44.4\%), drug use (7.2\%), legal (49.2\%) and social-family relationship (10.7\%). Those reported to have never injected drugs in the last 30 days had lower ASI total scores than those who reported injection drug use $(p=0.01)$. After identifying the differences in ASI total scores, we found there were significant associations in the clients' hepatitis C status, age category, frequency of heroin injection, quality of life score, marital status, current leisure status with family/friend, current history of injection in the last 30 days, income status, satisfaction with current marital status, as well as reported drug and alcohol use $(p<0.05)$. Stepwise binary logistic regression showed that alcohol and higher frequency of heroin injection were associated with higher ASI scores. Meanwhile, older age, respondents those who had leisure time with family, and satisfied with current marital status had lower ASI scores $(p<0.05)$.
\end{abstract}

Conclusion: Our results indicate that those enrolled in the MMT program in Myanmar faced many challenges in their daily social functioning. Treatment providers must take heed of these apparent impediment to ensure clients chequered social functioning does not undermine their treatment compliance.

Trial registration: NA

Keywords: Methadone maintenance therapy, Opioid addiction, Addiction severity index (ASI), Illicit drug use, Myanmar

${ }^{*}$ Correspondence: suntun1@gmail.com

${ }^{1}$ Myanmar Medical Association, Yangon, Myanmar

Full list of author information is available at the end of the article

\section{Background}

The United Nations Office on Drugs and Crime (UNODC) estimated that there are about 57.8 million opioid users globally [1]. The UNODC found that almost half of those who injected drugs were living with HIV original author(s) and the source, provide a link to the Creative Commons licence, and indicate if changes were made. The images or other third party material in this article are included in the article's Creative Commons licence, unless indicated otherwise in a credit line to the material. If material is not included in the article's Creative Commons licence and your intended use is not permitted by statutory regulation or exceeds the permitted use, you will need to obtain permission directly from the copyright holder. To view a copy of this licence, visit http://creativecommons.org/licenses/by/4.0/. The Creative Commons Public Domain Dedication waiver (http://creativeco mmons.org/publicdomain/zero/1.0/) applies to the data made available in this article, unless otherwise stated in a credit line to the data. 
and one in eight injectors had hepatitis C [2]. Opioid substitution therapy (OST) with methadone maintenance treatment (MMT) is the most promising harm reduction intervention for reducing illicit opioid use [3]. Although MMT is shown to curtail HIV spread and improve health, it is also equally important to evaluate clients social functioning in the MMT program [4]. A systematic review and meta-analysis of methadone treatment report a decrease in the self-reported arrest rate, clients' drug selling rate, rates of selling sex for drugs and drug-related crime from the baseline to 6 month and 12 months of intervention. Moreover, the rate of employment and proportion of clients reporting a good relationship with their family increased substantially after treatment started [5].

In Myanmar, the MMT programme was first introduced in 2006 primarily to curb HIV spread among injecting drug users. As of 2019, a total of 19,991 people who inject drugs (PWIDs) have enrolled in the MMT program in Myanmar [6]. With the support of public and private sectors who work collectively to mitigate HIV spread, both sectors were also responsible for ensuring the MMT program functions effectively. The National Strategic Plan for HIV/AIDS (2021-2025) plans to ensure that $40 \%$ of PWIDs in 2025 are enrolled in the MMT programme. Since clients in the MMT program are bound to face impairments in social functioning, it is vital for treatment providers to identify factors undermining clients social functioning during the MMT treatment including factors affecting the ASI. A qualitative interview on methadone patients in Myanmar found out that lack of an individualized treatment plan made it difficult to maintain the treatment and resulted in poor outcomes [7]. The research conducted in Yangon reported that the infection rates of HIV, HCV and HBV among those enrolled in methadone were high. It showed that their testing and subsequent treatment could be improved by the health education session of the methadone program, which also prevented further transmission to their community and the public. Furthermore, it was also recommended the development of participant-focused and more decentralized services of a methadone programme would prevent clients from leaving of methadone program [8]. Meanwhile, the research on social factor identification of the methadone clients in Myanmar is still a gap in the methadone literature.

Where injecting drug use (principally opioids) was one of the leading causes of HIV transmission, stopping injecting drug use led to a slowing down in the progression of HIV disease in infected subjects. But placing PWIDs on methadone treatment is not a complete solution. If the patients are retained on OST longer will have better outcomes. A high methadone dose, a key determinant of treatment retention with $60 \mathrm{mg}$ or greater, is also associated with improved retention and outcomes.
Furthermore, improved outcomes are also associated with provisional treatment of primary and specialist medical treatment, psychosocial support services and a range of ancillary services [9]. Treatment retention at 6 months was reported as high, uniformly averaging 70\% across the countries in that Lawrinson study. Meanwhile, recent data from Myanmar also reported 68\% retention in the program data [10].

In the prospective mixed methods cohort study in Imphal, India (a border area with Myanmar), the provision of OST caused significant reductions in needle sharing, in drug use over the previous 4 weeks, in property crime, anxiety, depression and suicidal thoughts when compared to the baseline and 12 months after treatment. Additionally, meaningful improvements in physical health, mental health, the quality of family relationships, and participation in family events, employment and hope for the future were reported from this cohort study. The study also included dropped-out clients from the methadone program with enrich understanding of the lived experience of OST clients. In the review of mental health and addiction services, the qualitative aspect of a family-centred approach to care was seen as an essential component, rather than client centre approach, especially in an Asian culture [11]. Another longitudinal research reported from Poland also acknowledged that methadone patients significantly changed their coherence; their lives are more understandable, predictable and meaningful, with the realization of all developmental tasks. However, their cognitive emotional regulation strategies and intensity of psychopathological symptoms did not change significantly after 6 months of treatment [12].

Given that clients in the MMT program are susceptible to experiencing social impairments, this study aims to generally define MMT client social functioning and identify factors undermining their social functioning in MMT treatment in Myanmar.

\section{Methods \\ Study design, respondents and location}

A total of 210 clients receiving methadone treatment participated in this cross-sectional study. All the respondents for this study were recruited through stratified random sampling from five cities (Yangon, Mandalay, Lashio, Kawlin and Mohnyin) in Myanmar where the MMT program is formally implemented. Each site from all of the States and Regions was included to ensure different client and provider characteristics were reflected. Data collection area sampling was done by randomizing the eligible sites based on the sample size requirements. A randomized plan for sampling site was created on www. randomization.com, and the data were used for selecting the study sites for Kachin, Shan, Sagaing, Mandalay and Yangon. Since the respondents were vulnerable and 
marginalized in nature, patients who gave the consent to answer the survey questionnaires and to give urine specimen were recruited randomly by the drop-in-centre service providers/resource people from the eligible candidate list (i.e. at least 6 month treatment) until the proposed sample size of 42 respondents was reached from each site. Personal interview and urine sample collection procedures were done in a private room at the drop in centres/ restaurant by the researchers at each site who were working on harm reduction projects. The addiction severity index-Lite (ASI) [13] with structured questionnaires was used to objectively determine respondents social functioning.

\section{Inclusion and exclusion criteria}

Inclusion criteria for the study include: (1) must be above 18 years of age, (2) presently enrolled in MMT programme and tested positive for methadone in urine and (3) must have a minimum of six-month MMT history. We included the exclusion criteria that those who hesitate to give their informed consent and those experiencing significant health and psychological problems. However, there were no clients excluded with these criteria in this study during the actual recruitment process and it can be assumed that the respondents' social functioning status was covered.

\section{Measures}

All the study data were collected from May to July 2017. All the surveys were conducted through face-to-face interviews by two trained researchers. A semi-structured questionnaire was used to collect respondents' socio-demographic characteristics, quality of life information, HIV risk behaviours, previous drug use history, and history of infectious disease and methadone treatment experiences. We also used the validated addiction severity index-Lite (ASI) [14], WHOQOL-BREF [15] and time line follow back (TLFB survey) [16] questionnaires to collect respondents drug use history. TLFB was added for accurate recall of the recent drug use status (previous 7 days) of the respondents, in addition to the ASI questionnaire.

For the addiction severity index (ASI) scores, 5 out of 7 composite scores were collected and analysed for employment, alcohol use, drug use, legal status and family/social composite scores. Medical and psychiatric composites were excluded. Each raw composite score was calculated and transformed to a $0-100$ scale using the formula shown below: where "Actual raw score" is the values achieved through the summation of responses from each composite score, "lowest possible raw score" is the lowest possible value that could occur through the summation (this value would be 4 for all facets of employment) and "Possible raw score range" is the difference between the maximum possible raw score and the lowest possible raw score.

\section{Urinalysis}

All the respondents were screened for methadone use prior to their participation in the study. Rapid test kits were used to confirm the respondents' illicit drug use status for morphine, cannabis, methamphetamine, amphetamine and benzodiazepine use. Rapid urine drug test kits were ordered from BioTesT (China) [17]. Rapid test strips were used after immersing in the urine specimen for 10-15 s, and then, the results could be read after $5 \mathrm{~min}$. The cut-off values established by the manufacturer of the urine tests were methadone above $300 \mathrm{ng} / \mathrm{ml}$, morphine above $300 \mathrm{ng} / \mathrm{ml}$, cannabinoids (THC) for marijuana above $50 \mathrm{ng} / \mathrm{ml}$, methamphetamine above $1000 \mathrm{ng} / \mathrm{ml}$, amphetamine above $1000 \mathrm{ng} /$ $\mathrm{ml}$ and benzodiazepine above $300 \mathrm{ng} / \mathrm{ml}$.

\section{ASI composite score calculation Composite score for employment status}

ASI composite score for employment status was included questions on driver's license and car availability for their use, paid work in the past 30 days, income from work in the past 30 days. Those responses were combined and transformed to 0-100 scale for comparison among the responses.

Our ASI calculation for the ASI score (Employment) and other ASI domain calculation technique was referred per Composite Scores Manual [14].

ASI calculation for employment score, there are 4 specific questions under the employment status.

A. Do you have a valid driver's license?

B. Do you have an automobile available for your use?

C. How many days were you paid for working in the past 30?

D. How much did you receive from employment (new income) in the past 30 days?

Step 1 Composite score for employment status is calculated with the formula " $1.000-(\mathrm{A} / 4+\mathrm{B} / 4+\mathrm{C} / 120$

$$
\text { Transformed scale }=\frac{(\text { Actual raw score }- \text { lowest possible raw score })}{\text { Possible raw score range }} \times 100
$$


$+\log \mathrm{D} / 36)$ " and we derive raw composite score from employment questions.

Step 2 The ASI raw score for "Employment domain" comes with the range from -0.87 to +1.69 and resulted total range 2.56. As different range of ASI scores for different domains varies (e.g. alcohol $(-2.08$ to +1.17 , range 3.25 , etc.), it is difficult to interpret with unequal total ranges. So, we applied the transformed scale formula to compare different ranges of raw score of different domains to " $0-100$ " scale, which can be easily seen the severity in percent score for all domains. illegal activity for profit in past 30 days and the amount of money received from illegal sources in the past 30 days. Legal status-related responses were combined and transformed to 0-100 scale for comparison among the responses.

\section{Composite score for family/social status}

The composite score for family/social status was derived from the responses to the questions on satisfaction with current marital situation, serious conflicts with their family in the past 30 days, family problems which trou-

$$
\text { Transformed scale }=\frac{(\text { Actual raw score }- \text { lowest possible raw score })}{\text { Possible raw score range }} \times 100
$$

This similar approach of calculation for the rest of the domains is referred as described by the Composite Scores Manual, and results are described in percent in Table 2 [with employment (47.4\%), alcohol (44.4\%), drug use $(7.2 \%)$, legal $(49.2 \%)$ and social-family relationship $(10.7 \%)]$.

\section{Composite score for alcohol use}

The composite score for alcohol use was derived from the responses to the questions of the number of days of any alcohol use/ intoxication in the past 30 days, the number of days troubled or bothered by any alcohol problems, how it was troubled in the past 30 days, the importance of treatment for alcohol problems and money spent during the past 30 days on alcohol. Alcohol-related responses were combined and transformed to $0-100$ scale for comparison among the responses.

\section{Composite score for drug use}

The composite score for drug use was derived from the responses to the questions of number of days use of drugs (heroin, methadone, other opiates/analgesics, barbiturates, other sedatives, cocaine, amphetamines, cannabis, hallucinogens), number of days used more than one drug, number of days drug use problems were experienced in the past 30 days, how the patient was troubled in the past 30 days and how important they viewed treating their drug problems. Drug use-related responses were combined and transformed to $0-100$ scale for comparison among the responses.

\section{Composite score for legal status}

The composite score for legal status was derived from the responses to the questions on status of presently awaiting charges, trial, or sentencing, number of days engaged in bled or bothered the patient in the past 30 days and how important they thought treatment or counselling was for their family problems. Responses were combined and transformed to 0-100 scale for comparison among the responses.

\section{Composite score for medical status and psychiatric status}

The composite scores for medical status and psychiatric status were not included. Those respondents who couldn't answer the survey questions due to medical and psychiatric problem were excluded from the client selection criteria. So, these two sessions in the ASI were omitted.

\section{Statistical analysis \\ Use of statistical tests}

The study data were analysed with Stata14.0 software. The responses were summarized and respective composite scores, and total scores were calculated. Chi-square test and Fisher's exact test were used for identifying association of the ASI score differences between categorical variables. Independent $\mathrm{t}$-tests were used to compare different types of respondent characteristics for continuous variables. For examining the differences between mean ASI scores of the interested parameters, independent $\mathrm{t}$-tests were used for analysis. Due to the limitation of the data availability on the interested vulnerable population, effect size indexes (e.g. Cohan's $d$ ) were not taken into considered for the estimation of sample size requirement and its analysis. Missing or incomplete entries were not counted in the formula calculation to achieve a composite score or average ASI score and to have a reliable and consistent calculation. A higher ASI score reflects a poorer functioning situation, and lower ASI scores reflect better functioning of the clients. Binary logistic regression was used for identifying the predictors to the interested outcome "ASI total score". Stepwise binary logistic 
regression analysis was done to recheck the significant regression output with the intended output by adjusting the confounding associated variables. All outcomes were set with statistically significance at $p<0.05$ with twotailed results.

\section{Ethical consideration}

Ethical approval for the study was obtained from the Human Ethics and Research Committee of Universiti Sains Malaysia (No: USM/ JEPeM/16080269) (University of Science, Malaysia) and Department of Medical Research (No: Ethics/DMR/2017/057), Ministry of Health and Sports, Myanmar [18].

\section{Results}

Socio-demographic characteristics

Respondents' socio-demographic characteristics are shown in Table 1. Respondent average methadone dose in this study was $83 \mathrm{mg} /$ day (with a range of between 20 and $300 \mathrm{mg} /$ day). Meanwhile, 132 (63.46\%) received a daily methadone dose of less than and equal $80 \mathrm{mg}$, while 76 (36.54\%) had more than $80 \mathrm{mg}$. The respondents mean duration of methadone treatment history in this study was 28 months (2.4 years). Eighty-three percent $(173 / 210)$ had one episode of methadone treatment history, while the rest had more than one episode of treatment history. A total of 210 respondents were recruited, 42 from each city in Kawlin (Sagaing), Lashio (Shan), Mandalay (Mandalay), Mohnyin (Kachin), Yangon (Yangon).

\section{Scores on addiction severity index}

To reflect the severity index of the clients, ASI scores were calculated as shown in Table 2. Some ASI composite questions were not answered, and some are not applicable for the respondents so are not meaningful to

Table 1 Demographic characteristics of methadone respondents

\begin{tabular}{|c|c|c|c|}
\hline Variable & Frequency ( $\mathrm{n}$ and \%) & Mean (SD) & Range \\
\hline Age (years) & & $33.35(8.85)$ & $20-76$ \\
\hline Less than and equal 35 years & $129(61.4 \%)$ & & \\
\hline more than 35 years & $81(38.6 \%)$ & & \\
\hline \multicolumn{4}{|l|}{ Gender } \\
\hline Male & $207(98.6 \%)$ & & \\
\hline Female & $3(1.4 \%)$ & & \\
\hline BMI (body mass index) & $206(98 \%)$ & $20.52(3.38)$ & $14.03-33.39$ \\
\hline Less than 18.5 (underweight) & 61 (29.61\%) & & \\
\hline Between 18.5 and 25 (normal) & $123(59.71 \%)$ & & \\
\hline More than 25 (overweight) & $22(10.68 \%)$ & & \\
\hline \multicolumn{4}{|l|}{ Working as outreach or peer } \\
\hline Yes & $29(13.81 \%)$ & & \\
\hline No & $181(86.19 \%)$ & & \\
\hline \multicolumn{4}{|l|}{ Education (years) } \\
\hline No formal education & $6(2.86 \%)$ & & \\
\hline Primary & $42(20 \%)$ & & \\
\hline Secondary (Middle + High School) & $117(55.71 \%)$ & & \\
\hline College- University & $45(21.43 \%)$ & & \\
\hline \multicolumn{4}{|l|}{ Marital status } \\
\hline Married & $84(40.58 \%)$ & & \\
\hline Separated/divorce/widowed & $27(13.04 \%)$ & & \\
\hline Single & $96(46.38 \%)$ & & \\
\hline \multicolumn{4}{|l|}{ Living style in recent 3 year period } \\
\hline Nuclear family style & $72(34.45 \%)$ & & \\
\hline With parents & $91(43.54 \%)$ & & \\
\hline Extended family & $41(19.62 \%)$ & & \\
\hline Alone & $5(2.39 \%)$ & & \\
\hline \multicolumn{4}{|l|}{ Employment (usual/last) } \\
\hline Employed & $192(91.43 \%)$ & & \\
\hline Un-employed currently (includes disable, student) & $18(8.57 \%)$ & & \\
\hline
\end{tabular}


Table 2 Table showing ASI scores (transformed on 0-100 scale)

\begin{tabular}{lcr}
\hline Variable & Frequency $(\mathbf{n}$ and \%) & Mean (SD) \\
\hline ASI total score & $210(100 \%)$ & $84.66(43.30)$ \\
ASl average score & $210(100 \%)$ & $23.97(10.49)$ \\
ASI composite scores & & \\
ASI for employment & $207(98.6 \%)$ & $47.38(19.15)$ \\
ASI for alcohol use & $64(30.5 \%)$ & $44.39(21.12)$ \\
ASI for drug use & $210(100 \%)$ & $7.2(13.39)$ \\
ASI for legal status & $28(13.3 \%)$ & $49.21(25.44)$ \\
ASI for family/social status & $210(100 \%)$ & $10.72(12.70)$ \\
\hline
\end{tabular}

interpret from incomplete answers. This causes the varying frequency for each composite scores as described in the table. As there are no data for ASI for medical and psychiatry, these composite scores are not mentioned in the ASI composite score table.

From the calculated ASI total scores derived from different domains, mean score differences with the respondents' characteristics are analysed in Table 3 [19].

The ASI total score was calculated by totalling the transformed score of each ASI domains for an individual. A high ASI total score was defined as a score above the mean score for the ASI total score of all eligible respondents.

From mean ASI score difference analysis, higher addiction severity index total scores $(p<0.05)$ were highly associated with methadone clients in the younger age group, currently employed, single or separated, low income, clients who were not satisfied with current marital status, marital status as single/ separated, who had less quality of life (Physical and environmental domains), clients not satisfied with current leisure status and clients with hepatitis $C$ infection. However, there were no significant differences of ASI total scores and subscores between different categories of methadone dose $(p>0.05)$. Meanwhile, there were significant differences of ASI total scores on employment and alcohol use. These scores were significantly higher among clients with longer treatment on methadone $(p<0.05)$. ASI score differences with the illicit drug use situation are further analysed in Table 4.

\section{Urinalysis finding}

Results from the urine drug screening show 117 (55.71\%) tested for morphine, 54 (25.71\%) for amphetamine and methamphetamine, 25 (11.90\%) for THC, a cannabis compound and $72(34.29 \%)$ for benzodiazepine. More than two-thirds tested for only one type of drug, while 92 (43.81\%) were identified as poly-drug users.

From additional data analysis, ASI drug use scores were significantly higher among clients who injected heroin in the last 30 days and also reported higher frequency of drug injection $(p<0.05)$. Those reported to have never injected drugs in the last 30 days had lower ASI total scores than those who reported injection drug use $(p=0.00)$. Needle sharing in the last 30 days, as well as needle sharing in their life time, was seen among clients with a high ASI employment score $(p<0.05)$. Those clients who reported alcohol and drug use (alcohol, heroin, benzodiazepine, antidepressant, THC, inhalants) and poly-drug use had higher ASI scores $(p<0.05)$.

After identifying the differences in ASI total scores, factors associated with high ASI scores were explored. There was significant association between higher ASI total scores of methadone clients who had hepatitis $\mathrm{C}$, younger age, higher frequency of heroin injection, respondents with lower quality of life score, marital status as single/ separated, respondents who are not satisfied current leisure status with family/friend/or alone, higher injections per month currently, low-income status, not satisfied with current marital status, reported drug and alcohol use among variables mentioned in the tables. For drug and alcohol use, alcohol, heroin, morphine, benzodiazepine, antidepressant, THC, inhalant and those who use more than one drug were associated with higher ASI total scores $(p<0.05)$. These significant parameters were put for further regression analysis.

\section{Stepwise binary logistic regression analysis}

After considering significant association factors in the model affecting ASI total scores (based on significant parameters in Tables 3, 4), stepwise binary logistic regression was done to identify predictors that were linked with high ASI total scores. Retention in logistic regression was used for predicting client characteristics impacted on the total score of addiction severity index. When checking for multi collinearity, the mean variance inflation factor (vif) was 1.89 and none of the variables has more than 10 . The regression model alpha ratio is set at 0.05 .

Table 5 shows the result of stepwise binary logistic regression.

In the analysis of adjusted model of binary logistic regression, potential confounding variables (among associated characteristics) were considered for adjustment and estimated the association of independent variables to the outcome (dependent) variable of total score of addiction severity index of the methadone clients. Alcohol alone had 24 times (aOR 24.47, 95\% CI 6.14-97.51, $p=0.000$ ) while higher frequency of heroin injection had 4 times (aOR 4.11, 95\% CI 1.37-12.35, $p=0.012$ ) in contributing high addiction severity score of the clients. Being older than 35 years had 8 times (aOR 0.12, 95\% CI $0.05-0.37, p=0.000$ ), and leisure with the family reduced 
Table 3 Table showing differences of mean ASI total score with characteristics of the respondents

\begin{tabular}{|c|c|c|c|c|}
\hline Demographic characters & Sub groups & Number (n) & $\begin{array}{l}\text { Mean ASI total } \\
\text { score }\end{array}$ & $p$ value \\
\hline \multirow[t]{2}{*}{ Age } & Younger and equal 35 years & 129 & 88 & $0.0247^{* *}$ \\
\hline & Older than 35 years & 81 & 80 & \\
\hline \multirow[t]{2}{*}{ BMI (body mass index) } & Less than mean BMI (20.5) & 122 & 88 & 0.2183 \\
\hline & More than mean BMI & 84 & 80 & \\
\hline \multirow[t]{2}{*}{ Antiretrovials (ART) } & No & 142 & 84 & 0.6534 \\
\hline & On treatment & 68 & 87 & \\
\hline \multirow[t]{2}{*}{ Education } & Up to primary & 48 & 85 & 0.9893 \\
\hline & More than primary & 162 & 85 & \\
\hline \multirow[t]{2}{*}{ Job status } & Unemployed & 24 & 80 & $0.0000 * * *$ \\
\hline & Employed & 183 & 118 & \\
\hline \multirow[t]{2}{*}{ Current peer/ outreach worker } & No & 181 & 87 & 0.0556 \\
\hline & Peer/outreach & 29 & 70 & \\
\hline \multirow[t]{2}{*}{ Marital status } & Currently married & 84 & 70 & $0.0000^{* * *}$ \\
\hline & Single/separated & 123 & 95 & \\
\hline \multirow[t]{2}{*}{ Income } & Low & 131 & 97 & $0.0000^{* * *}$ \\
\hline & High & 78 & 65 & \\
\hline \multirow[t]{2}{*}{ Current marital status satisfaction } & Not satisfied & 20 & 108 & $0.0098^{* *}$ \\
\hline & Satisfied & 190 & 82 & \\
\hline \multirow[t]{2}{*}{ WHO Quality of life (QOL) total score } & Low & 88 & 98 & $0.0002^{* * *}$ \\
\hline & High & 121 & 75 & \\
\hline \multirow[t]{2}{*}{ Physical QOL score } & Low & 53 & 99 & $0.0062 * *$ \\
\hline & High & 156 & 80 & \\
\hline \multirow[t]{2}{*}{ Psychological QOL score } & Low & 41 & 90 & 0.3739 \\
\hline & High & 168 & 83 & \\
\hline \multirow[t]{2}{*}{ Social QOL score } & Low & 71 & 93 & 0.0584 \\
\hline & High & 138 & 81 & \\
\hline \multirow[t]{2}{*}{ Environmental QOL score } & Low & 54 & 98 & $0.0111 * *$ \\
\hline & High & 155 & 80 & \\
\hline \multirow[t]{2}{*}{ Current leisure status satisfaction } & Not satisfied & 30 & 106 & $0.0032^{* *}$ \\
\hline & Satisfied & 180 & 81 & \\
\hline \multirow[t]{2}{*}{ Current leisure status with family } & Not satisfied & 120 & 97 & $0.0000^{* * *}$ \\
\hline & Satisfied & 90 & 68 & \\
\hline \multirow[t]{2}{*}{ Current leisure status with friend } & Not satisfied & 135 & 79 & $0.0200^{* *}$ \\
\hline & Satisfied & 75 & 94 & \\
\hline \multirow[t]{2}{*}{ Current leisure status alone } & Not satisfied & 160 & 80 & $0.0059^{* *}$ \\
\hline & Satisfied & 50 & 99 & \\
\hline \multicolumn{5}{|l|}{ Infection history } \\
\hline \multirow[t]{2}{*}{ HIV status (No vs Yes) } & Not infected & 126 & 82 & 0.4194 \\
\hline & Infected & 74 & 87 & \\
\hline \multirow[t]{2}{*}{ Hepatitis C status } & Not infected & 77 & 78 & $0.0162^{* *}$ \\
\hline & Infected & 71 & 95 & \\
\hline \multirow[t]{2}{*}{ Hepatitis B status } & Not infected & 166 & 83 & 0.4711 \\
\hline & Infected & 15 & 94 & \\
\hline Tuberculosis treatment history & No history & 147 & 87 & 0.2669 \\
\hline & Treated history & 54 & 79 & \\
\hline Sexually transmitted infection history & No history & 164 & 84 & 0.7533 \\
\hline & Infected history & 45 & 87 & \\
\hline Abuse encountered within 30 days & Not experienced & 183 & 83 & 0.3155 \\
\hline & Experienced & 26 & 93 & \\
\hline
\end{tabular}


Table 3 (continued)

\begin{tabular}{|c|c|c|c|c|}
\hline Demographic characters & Sub groups & Number (n) & $\begin{array}{l}\text { Mean ASI total } \\
\text { score }\end{array}$ & $p$ value \\
\hline \multirow[t]{2}{*}{ Psychological abuse } & Not experienced & 184 & 83 & 0.3703 \\
\hline & Experienced & 22 & 92 & \\
\hline \multirow[t]{2}{*}{ Physical abuse } & Not experienced & 204 & 85 & \\
\hline & Experienced & 1 & 93 & \\
\hline \multirow[t]{2}{*}{ Sexual abuse } & Not experienced & 205 & 84 & \\
\hline & Experienced & 1 & 62 & \\
\hline \multicolumn{5}{|l|}{ Methadone services } \\
\hline \multirow[t]{2}{*}{ Methadone dose categories } & Less than and equal $80 \mathrm{mg}$ & 132 & 87 & 0.4118 \\
\hline & More than $80 \mathrm{mg}$ & 76 & 82 & \\
\hline \multirow[t]{2}{*}{ Methadone duration } & Less than and equal 2.4 year & 120 & 85 & 0.8608 \\
\hline & More than 2.4 year & 89 & 84 & \\
\hline \multirow[t]{2}{*}{ Methadone treat frequency } & First time treatment & 173 & 84 & 0.5357 \\
\hline & More than one time & 35 & 89 & \\
\hline \multirow[t]{2}{*}{ Dose less than and equal $80 \mathrm{mg}$} & First time treatment & 109 & 86 & 0.7544 \\
\hline & More than one time & 22 & 89 & \\
\hline \multirow[t]{2}{*}{ More than $80 \mathrm{mg}$} & First time treatment & 63 & 80 & 0.5339 \\
\hline & More than one time & 13 & 88 & \\
\hline \multirow[t]{2}{*}{ Duration less than and equal 2.4 years } & First time treatment & 95 & 85 & \\
\hline & More than one time & 24 & 82 & 0.7389 \\
\hline \multirow[t]{2}{*}{ More than 2.4 years } & First time treatment & 78 & 82 & 0.1795 \\
\hline & More than one time & 11 & 102 & \\
\hline
\end{tabular}

Independent t-test $p$ value: ** significance $<0.05,{ }^{* * *}$ significance $<0.001$

addiction severity by 4 times among methadone clients (aOR 0.12, 95\% CI 0.04-0.37, $p=0.000$ ). Satisfaction with current marital status also lessened severity by 8 times among methadone clients (aOR 0.12, 95\% CI 0.03-0.57, $p=0.008)$.

Significant differences of ASI scores from logistic regression were seen among the client with different characteristics mentioned in Fig. 1.

\section{Discussion}

To the best of our knowledge, this study is among the few available studies that aim to describe MMT clients social functioning in Myanmar. Various studies have shown that clients who are enrolled in the MMT program have better ASI scores or social functioning [20]. We found alcohol and frequency of heroin injection significantly influenced ASI scores. Since the majority of clients were still using drugs, alcohol consumption also highly influenced clients social functioning. High scores on ASI were observed among those reported drug and alcohol use and also among poly-drug users $(p<0.05)$. In another 10 -year follow-up study, alcohol highly influenced to the drug use and ASI drug scores were also significant $(p=0.0008)$ [21]. Those who used drugs and alcohol had higher ASI scores in the drug use domain $(p<0.05)$. These findings were in accordance with a previous study [22]. Consequently, an increase in ASI scores for alcohol use was also a strong predictor for dropping out from the MMT program [23].

There were no significant differences in the ASI total scores with methadone dose and duration of treatment. In another longitudinal study, there were significant differences in the ASI drug use domain $(p=0.0002)$ among clients receiving high methadone dose (more than $100 \mathrm{mg})$ and the ASI family domain $(p=0.03)$ among those receiving moderate doses of methadone (60-100 mg), but significant improvement in the ASI score for drugs in high dose group [24]. A significant finding of Fareed study which contributed to better understanding of these clients was the prospective cohort analysis of the clients. Meanwhile, our current result is from cross-sectional study without eliminating other confounding factors like enzyme inducers in patients taking other treatments (e.g. antiretrovials). This finding was similar to another study showing that those receiving higher methadone doses were (a) HIV infected and (b) HIV and hepatitis C co-infected compared to those without HIV and hepatitis $\mathrm{C}$ infections $(p<0.0001)$ as described in the PROTEUS study [25]. This affects methadone dose and has a significant 
Table 4 Differences of mean ASI total score with illicit drug use situation of respondents

\begin{tabular}{|c|c|c|c|c|}
\hline $\begin{array}{l}\text { Differences in ASI score with illicit drug use } \\
\text { situation }\end{array}$ & Sub groups & Number (n) & Mean ASI total score & $p$ value \\
\hline \multicolumn{5}{|l|}{ Urine illicit drug findings } \\
\hline \multirow[t]{2}{*}{ Urine morphine } & Absent & 93 & 85 & 0.8683 \\
\hline & Present & 117 & 84 & \\
\hline \multirow[t]{2}{*}{ Urine THC } & Absent & 185 & 83 & 0.1104 \\
\hline & Present & 25 & 98 & \\
\hline \multirow[t]{2}{*}{ Urine methamphetamine } & Absent & 158 & 85 & 0.6610 \\
\hline & Present & 52 & 82 & \\
\hline \multirow[t]{2}{*}{ Urine amphetamine } & Absent & 191 & 86 & 0.2132 \\
\hline & Present & 19 & 73 & \\
\hline \multirow[t]{2}{*}{ Urine benzodiazepine } & Absent & 138 & 83 & 0.3846 \\
\hline & Present & 72 & 88 & \\
\hline \multicolumn{5}{|l|}{ Reported drug use status } \\
\hline \multirow[t]{2}{*}{ Last heroin injection within 30 days } & No & 93 & 75 & $0.0030^{* *}$ \\
\hline & Yes & 116 & 93 & \\
\hline \multirow[t]{2}{*}{ Frequency of injection per month } & No or few inj: $($ mean $=7)$ & 162 & 80 & $0.0011^{* * *}$ \\
\hline & Higher & 47 & 103 & \\
\hline \multirow[t]{2}{*}{ Needle sharing within 30 days } & Not shared & 99 & 92 & $0.0160^{* *}$ \\
\hline & Shared & 4 & 150 & \\
\hline \multirow[t]{2}{*}{ Life time sharing of needle and syringes } & Not shared & 106 & 79 & $0.0478^{* *}$ \\
\hline & Shared & 103 & 91 & \\
\hline \multirow[t]{2}{*}{ Drug and alcohol } & Not used & 47 & 60 & $0.0000^{* * *}$ \\
\hline & Used & 162 & 92 & \\
\hline \multirow[t]{2}{*}{ Alcohol } & Not used & 144 & 71 & $0.0000^{* * *}$ \\
\hline & Used & 66 & 115 & \\
\hline \multirow[t]{2}{*}{ Heroin } & Not used & 117 & 78 & $0.0073^{* *}$ \\
\hline & Used & 93 & 94 & \\
\hline \multirow[t]{2}{*}{ Morphine } & Not used & 205 & 84 & $0.0508^{* *}$ \\
\hline & Used & 5 & 122 & \\
\hline \multirow[t]{2}{*}{ Benzodiazepine } & Not used & 187 & 82 & $0.0133^{* *}$ \\
\hline & Used & 22 & 106 & \\
\hline \multirow[t]{2}{*}{ Barbiturate } & Not used & 206 & 84 & 0.6641 \\
\hline & Used & 4 & 94 & \\
\hline \multirow[t]{2}{*}{ Antidepressant } & Not used & 206 & 83 & $0.0000^{* * *}$ \\
\hline & Used & 4 & 173 & \\
\hline \multicolumn{5}{|l|}{ Cocaine (Not used $=210$ ) } \\
\hline \multirow[t]{2}{*}{ Amphetamine } & Not used & 156 & 81 & 0.0646 \\
\hline & Used & 54 & 94 & \\
\hline \multirow[t]{2}{*}{ THC } & Not used & 186 & 82 & $0.0162^{* *}$ \\
\hline & Used & 24 & 105 & \\
\hline \multirow[t]{2}{*}{ Ecstasy } & Not used & 207 & 84 & 0.3084 \\
\hline & Used & 3 & 110 & \\
\hline \multirow[t]{2}{*}{ Inhalants } & Not used & 133 & 80 & $0.0391^{* *}$ \\
\hline & Used & 76 & 93 & \\
\hline \multirow[t]{2}{*}{ More than one drug } & Not used & 50 & 66 & $0.0005^{* * *}$ \\
\hline & Used & 143 & 90 & \\
\hline
\end{tabular}

Independent t-test $p$ value: ${ }^{* *}$ significance $<0.05,{ }^{* * *}$ significance $<0.001$ 
Table 5 Correlates of high ASI total score among methadone respondents

\begin{tabular}{lcc}
\hline Variables & Adjusted OR (95\% Cl) & $\boldsymbol{p}$ value \\
\hline Heroin injection frequency & $4.11(1.37,12.35)$ & $0.012^{* *}$ \\
Alcohol & $24.47(6.14,97.51)$ & $0.000^{* * *}$ \\
Age & $0.12(0.04,0.37)$ & $0.000^{* * *}$ \\
Leisure with family & $0.23(0.82,0.63)$ & $0.000^{* * *}$ \\
Satisfaction with marital status & $0.12(0.03,0.57)$ & $0.008^{* *}$ \\
\hline
\end{tabular}

Stepwise binary logistic regression, $p$ value: **significance $<0.05$, ***significance $<0.001$

correlation with $\mathrm{HCV}$ infection [26]. This indicates that clients with co-infections are prescribed with high methadone dose in Myanmar. Longer treatment duration had significant differences in the ASI employment score $(p=0.0029)$ and ASI alcohol use scores among MMT clients in this study $(p=0.0214)$. This was similar to the findings of a system review of ASI employment score results, reduced at follow-up from baseline with longer duration on methadone $(p=0.074)$ [20]. It was also discussed in similar context where MMT treatment itself exposed the clients with an additional burden which needs with implementation adjustments to include extending clinic hours, offering transportation services and providing take-home doses if feasible [27].
Opioid dependent clients identified by urine had higher ASI scores for employment and drug use $(p<0.05)$. Those who tested for opioid use were more likely to use benzodiazepine $(p=0.000)$. Benzodiazepine use was found to be common among MMT clients [28]. Furthermore, the benzodiazepine use is also a strong predictor for the drop out of the methadone clients within 12 months [29]. Use of benzodiazepine identified by urine in this study was associated with higher ASI scores for family $(p=0.0209)$, low dose methadone clients $(p=0.014)$ and clients who had longer MMT duration $(p=0.031)$.

From this study findings, those who wish to initiate OST treatment should be properly counselled with the correct aims and attitude of taking opioid substitution therapy. Identification of long-term methadone service utilization should be tracked for the changes of treatment parameters. Individualized data tracking can be done, but this has to be done in consideration with medical ethics. Use of the unique client coding system is essential in recording and linking of utilized services with patient treatment episodes and its addiction severity, behaviour changes linked with drug use and treatment. Satisfaction of friend and family support is also crucial in patient social functioning while having effective methadone treatment. This will improve the individual treatment scenario and program planning aspect for each

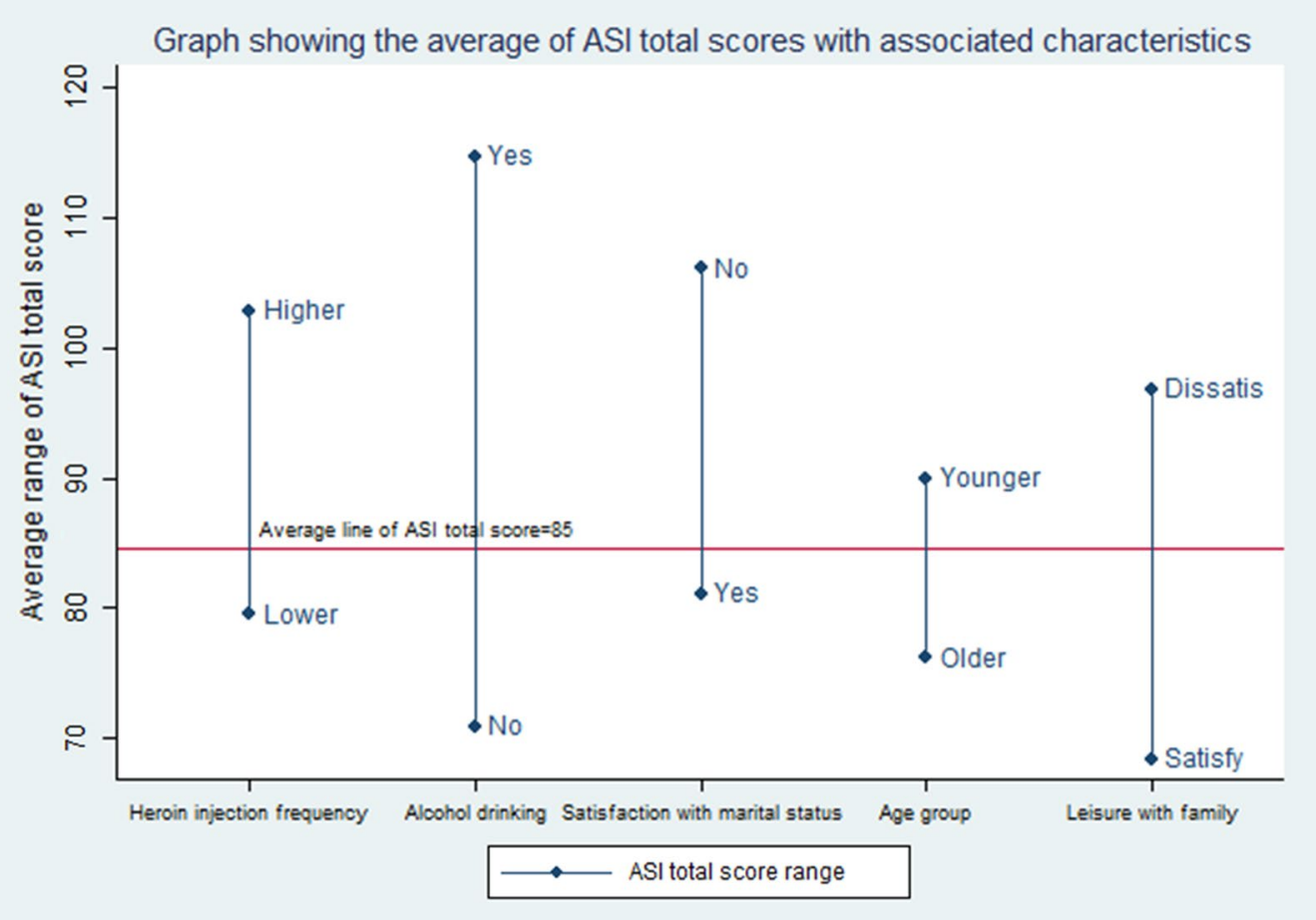

Fig. 1 Graph showing the average of ASI total scores with associated characteristics 
dispensing centres. These points were also highlighted for effective implementation of the OST in the resource poor settings, but not limited to the lack of political will to act, need to change the relevant laws, social and structural discrimination against PWIDs, cost of providing therapy and lack of local evidence [30].

This study has a few limitations. The cross-sectional study design is not possible to prove the parameter differences by the continuous timeline or causal interventions. Another limitation in the sampling is it needs to obtain the total methadone client population for the selected site (city). Due to national data privacy, the random selection was only supported by the harm reduction service providers who had access to the sampling frame. There could be limitation on randomness of selected participants from the selected site.

One additional limitation of this study is the low number of participation from female methadone users which can be due to low female drug use compared to male populations. Furthermore, this may also be due to cultural reasons where fewer female drug users seek treatment compared to male drug users and a lower female response was reflected. The study exclusion criteria also considered the medical and psychological domains as screening tools for patients who couldn't response well with these factors in participation the survey. Questions on seriousness on the feeling of present legal problems and importance of counselling or referral need for legal problems were not included due to privacy reason.

\section{Conclusion}

Our findings proved that there were significant influential factors that affected clients' social functioning in the MMT program in Myanmar. There is a need for treatment providers to give more attention to subtle factors affecting clients social functioning. As addiction scores are higher in employment, legal and alcohol, the study highlights a critical intervention need for proper psychosocial counselling and rehabilitation programme with employment supports for methadone clients. Besides, addressing pharmaceutical interventions, creating employment opportunities and enabling social factors like marital and family status satisfaction are also crucial for improving clients social functioning. Further studies are needed to determine clients social functioning in MMT program in Myanmar.

\section{Acknowledgements}

The authors would like to thank to all survey respondents and Dr. Nanda Myo Aung Wan, DDTRU Programme Manager, in Myanmar who supported in proposal development. Further appreciation goes to Dr. Ohnmar Thaung, U Thet Swe, Dr. Phyo Myat, Dr. Nay Lin, Dr. Myo Min Min and harm reduction organizations in Myanmar (Myanmar Anti-Narcotic Association, Burnet Institute, Asian Harm Reduction Network) for supporting survey data collection.

\section{Authors' contributions}

ST contributed in designing, implementation, analysis and wrote the manuscript. BV and DS contributed in designing, analysis and contributed in this manuscript.

\section{Funding}

Authors declared that the research and publication of their article were selffunded for academic purpose.

\section{Data availability}

The [.dta] data used to support the findings of this study are available from the corresponding author upon the approval of the Centre for Drug Research.

\section{Declarations}

\section{Ethical approval and consent to participate}

This research approval was granted from the Human Ethics Committee of the Universiti Sains Malaysia (No:USM/ JEPeM/16080269) (University of Science, Malaysia) and Department of Medical Research (No: Ethics/DMR/2017/057), Ministry of Health and Sports, [18].

\section{Consent for publication}

All authors read and approved final manuscript submission. All authors agree to publish this prepared manuscript and no other submission of this manuscript to other journal.

\section{Competing interests}

All authors declare that there is no competing interest.

\section{Author details}

${ }^{1}$ Myanmar Medical Association, Yangon, Myanmar. ${ }^{2}$ Centre for Drug Research, Universiti Sains Malaysia, George Town, Penang, Malaysia.

Received: 14 January 2021 Accepted: 10 July 2021

Published online: 05 August 2021

\section{References}

1. UNODC. "World Drug Report." 15. UNODC, 2020.

2. UNODC. "World Drug Report." In: Global overview of drug demand and supply, Latest trends, cross-cutting issues, 12. UNODC, 2018.

3. WHO. The methadone fix. WHO. 2008. https://wWw.who.int/bulletin/ volumes/86/3/08-010308/en/. Accessed 10 Sept 2020.

4. Bart G. Maintenance medication for opiate addiction: the foundation of recovery. J Addict Dis. 2012;31:207-25.

5. Sun $\mathrm{H}-\mathrm{M}$, et al. Methadone maintenance treatment programme reduces criminal activity and improves social well-being of drug users in China: a systematic review and meta-analysis. BMJ Open. 2015;5:e005997.

6. Myanmar, The Global Fund Programme. In: The Global Fund Programme in Myanmar. 2020. https://pr-myanmar.org/en/disease/hiv. Accessed 10 Sept 2020.

7. Soe ZN (2013) Methadone program in Burma (Myanmar): challenges faced by methadone patients. NIDA International. 2013.

8. Aye NS, et al. HIV, HBV and HCV in people who inject drugs and are placed on methadone maintenance therapy, Yangon, Myanmar. Public Health Action. 2018;8(4):202-10

9. Lawrinson P, et al. Key findings from the WHO collaborative study on substitution therapy for opioid dependence and HIV/AIDS. Addiction. 2008;103(9):1484-92.

10. 2019 HIV Reviews. MoHS Myanmar; 2019.

11. Kermode M, Choudhurimayum RS, Rajkumar LS, Haregu T, Armstrong G. Retention and outcomes for clients attending a methadone clinic in a resource-constrained setting: a mixed methods prospective cohort study in Imphal, Northeast India. Harm Reduct J. 2020;17:68.

12. Nalaskowska M, Cierpiałkowska L. Social and psychological functioning of opiate dependent patients in methadone maintenance treatment-longitudinal research report. Alcohol Drug Addict. 2014;27(3):237-54.

13. T McLellan, J Cacciola, D Carise, and TH Coyne. "Addiction Severity Index Lite - CF." 1999. 
14. McGahan PL, Griffith JA, Parente R, McLellan AT. Addiction severity index composite score manual. Philadelphia: The University of Pennsylvania/ Veterans Administration Center for Studies of Addiction, 1986.

15. WHO. The World Health Organization Quality of Life (WHOQOL)-BREF. 2004.

16. NIDA-CTN. Instrument: timeline followback method assessment. 2014. https://cde.drugabuse.gov/sites/nida_cde/files/TimeLineFollowBack_ 2014Mar24.pdf.

17. Hangzhou Biotest Biotech Co., LTD. Hangzhou Biotest Biotech Co., LTD. 2018. http://en.biotests.com.cn/.

18. Research, Department of Medical. http://www.ercdmrlm.org. 2017. http://www.ercdmrlm.org/pdf/2017_Certificate_List.pdf.

19. Tun S, Vicknasingam B, Singh DS. Factors affecting addiction severity index among methadone clients in Myanmar. In: 26th Harm Reduction International Conference (HR19) Porto, Portugal. Portugal: Harm Reduction International, 2019.

20. Feelemyer JP, Des Jarlais DC, Arasteh K, Phillips BW, Hagan H. Changes in quality of life (WHOQOL-BREF) and addiction severity index (ASI) among participants in opioid substitution treatment (OST) in low and middle income countries: an international systematic review. Drug Alcohol Depend. 2014;134:251-8.

21. Auriacombe $M$, et al. 10-years outcome of methadone- and buprenorphine-maintained patients. Mortality, quality of life and substance use. Drug Alcohol Depend. 2014;140:e2-85.

22. Robles E, Huang BE, Simpson PM. Delay discounting, impulsiveness, and addiction severity in opioid-dependent patients. J Subst Abuse Treat. 2011:41(4):354-62.
23. Jiang $\mathrm{H}$, et al. Factors associated with one year retention to methadone maintenance treatment program among patients with heroin dependence in China. Subst Abuse Treat (BMC). 2014;9:1-6.

24. Fareed $\mathrm{A}$, et al. High dose versus moderate dose methadone maintenance: is there a better outcome? J Addict Dis. 2009;28(4):399-405.

25. Roncero C, Fuster D, Palma-Álvarez RF, Cintas LR, Martinez-Luna N, Álvarez FJ. AIDS care. Routledge: Taylor \& Francis Group; 2017.

26. Wu S-L, et al. Hepatitis C virus infection influences the S-methadone metabolite plasma concentration. PLoS One PLoS. 2013:8(7):e69310.

27. Lin C-K, Hung C-C, Peng C-Y, Chao E, Lee TS-H. Factors associated with methadone treatment duration: a cox regression analysis. PLOS ONE. 2015;10:e0123687.

28. Ghitza UE, Epstein DH, Preston KL. Self-report of illicit benzodiazepine use on the addiction severity index predicts treatment outcome. Drug Alcohol Depend. 2008;97(1-2):150-7.

29. Durand $L$, et al. Factors associated with early and later dropout from methadone maintenance treatment in specialist addiction clinics: a sixyear cohort study using proportional hazards frailty models for recurrent treatment episodes. Drug Alcohol Depend. 2021;219:108466.

30. Kermode M, Crofts N, Suresh Kumar M, Dorabjee J. Opioid substitution therapy in resource-poor settings. Bull World Health Organ. 2011;89(4):241-316.

\section{Publisher's Note}

Springer Nature remains neutral with regard to jurisdictional claims in published maps and institutional affiliations.
Ready to submit your research? Choose BMC and benefit from:

- fast, convenient online submission

- thorough peer review by experienced researchers in your field

- rapid publication on acceptance

- support for research data, including large and complex data types

- gold Open Access which fosters wider collaboration and increased citations

- maximum visibility for your research: over $100 \mathrm{M}$ website views per year

At BMC, research is always in progress.

Learn more biomedcentral.com/submissions 